\title{
Research on driving factors of China's carbon emissions based on structural decomposition
}

\author{
Hua Gao ${ }^{1}$, Zhoujie Huang ${ }^{1, *}$ \\ ${ }^{1}$ School of Management, Tianjin University of Technology, Tianjin 300384, China
}

\begin{abstract}
After further processing the input-output tables of 2007, 2012 and 2017, the carbon emissions are decomposed into four driving factors: energy intensity effect, Leontief technology effect, final demand structure effect and final total demand effect through IO-SDA model. The results show that the energy intensity effect has a significant negative effect, which is the main factor to promote the reduction of carbon emissions. The Leontief technical effect and the final total demand effect are positive effects, and the total final demand effect is the main factor leading to the increase in carbon emissions, and the effect of the final demand structure effect is not significant. In addition, the results of the influence coefficient and the inductance coefficient show that: metal smelting and rolling manufacturing, petroleum processing and coking and nuclear fuel processing, coal mining and processing, and oil and gas mining and processing industries are high-energy-consuming industries, but the status of the basic industry makes it possible to formulate energysaving policies only in terms of technological progress.
\end{abstract}

\section{Introduction}

The research on the driving factors of carbon emissions mainly uses the index decomposition method (IDA) and structural decomposition method (SDA) to explore the influence factors of energy intensity, economic development level, industrial structure and technological progress on carbon emissions. The most widely used method in IDA is the logarithmic mean Divisia index decomposition (LMDI). Yang $\mathrm{Wu}$ et al. ${ }^{[1]}$ used this method at the regional level to decompose the carbon emissions of energy consumption in Wuhan. $\mathrm{Xu}$ Guo quan $^{[2]}$ and Zhu Qin ${ }^{[3]}$ used this method to analyze China's carbon emissions from the macro level of the country. Although IDA can make full use of the data of each year, it is easier to use and easier to operate, but it can't describe the relationship between different industries. The realization of SDA needs to use the input-output table to discuss from the perspective of different industries in the process of analysis. At the same time, according to the needs of research, different industrial sectors can be merged and discussed in a targeted way. Leontief. W. et al. ${ }^{[4]}$ first used SDA method to analyze the changes of air pollution emissions in the United States. In the decomposition of China's tourism carbon emissions, Zha Jianping ${ }^{[5]}$ used SDA decomposition method to decompose the carbon emission of tourism industry, and concluded that the direct carbon emission of tourism industry accounted for a relatively low proportion, and the carbon emission caused by it came from other sectors indirectly. In conclusion, the SDA method decomposes the change of carbon dioxide emissions in different periods into energy structure effect, energy intensity effect, industrial structure change effect and final demand effect by means of input-output table to measure the contribution of these factors to carbon emission. This paper chooses the energy intensity effect and the industrial structure effect when decomposing, and decomposes the final demand effect into the final demand structure effect and the final total demand effect. In addition, the influence coefficient and the inductance coefficient are also used to analyze and compare the important position of various industries in the economy and their mutual influence with the overall national economy.

\section{Construction of IO-SDA model}

\subsection{Construction of IO-SDA decomposition model}

Based on previous studies, this paper decomposes the carbon dioxide emission into the product of four driving factors and establishes the following IO-SDA model:

$$
\sum_{i=1}^{n} C_{i}=\sum_{i=1}^{n} \frac{C_{i}}{E_{i}} \sum_{i=1}^{n} \frac{E_{i}}{Y_{i}}(I-A)^{-1} U_{i}
$$

Among them, $C_{i}$ is the carbon emission of the $i$ sector; $\frac{C_{i}}{E_{i}}$ is the carbon emission per unit energy consumption, i.e. carbon emission coefficient, expressed by $F$.The final energy demand of the industry is calculated using the calculation method of coal consumption for power generation in the "China Energy

\footnotetext{
* Corresponding author: 964303359@qq.com
} 
Statistical Yearbook", so the carbon emission coefficient here is fixed; $\frac{E_{i}}{Y_{i}}$ is the output value of the $i$ department unit is the energy consumed source, namely energy intensity (energy consumption per unit of GDP), expressed by $T ;(I-A)^{-1}$ represents the economic structure, that is, the Leontief inverse matrix, using $L$ Means; $U_{i}$ is the final demand matrix. $U_{i}$ is further decomposed into $U_{i}^{t}$ and $U_{i}^{s}$, that is, the change effect of final demand structure and the total effect of final demand. Therefore, according to the structural decomposition method, the derivation is as follows:

$$
\begin{aligned}
\Delta C & =F T_{t} L_{t} U_{t}^{s} U_{t}^{v}-F T_{0} L_{0} U_{0}^{s} U_{0}^{v} \\
& \approx F\left(T_{t}-T_{0}\right) L U^{s} U^{v}+F T\left(L_{t}-L_{0}\right) U^{s} U^{v} \\
& +F T L\left(U_{t}^{s}-U_{0}^{s}\right) U^{v}+F T L U^{s}\left(U_{t}^{v}-U_{0}^{v}\right) \\
& =F \Delta T L U^{s} U^{v}+F T \Delta L U^{s} U^{v}+F T L \Delta U^{s} U^{v} \\
& +F T L U^{s} \Delta U^{v}+\Delta C_{r s d}
\end{aligned}
$$

In other words, the difference in carbon emissions is finally decomposed into energy intensity effects, technological progress effects (namely the Leontief inverse matrix effect), the final demand structure effect, and the final total demand effect, because the carbon emission coefficient is fixed and its effect is 0 .

The SDA decomposition method usually faces the problem of how to deal with the structural decomposition residual term. The structural decomposition residual term $\Delta C_{r s d}$ is the interaction of the effects of multiple factors on changes in carbon emissions. The first-order Taylor expansion of carbon emission change $\Delta C$ is:

$$
\begin{aligned}
\Delta C & =F \Delta T L_{i} U_{i}^{S} U_{i}^{v}+F T_{i} \Delta L U_{i}^{S} U_{i}^{v} \\
& +F T_{i} L_{i} \Delta U^{S} U_{i}^{v}+F T_{i} L_{i} U_{i}^{S} \Delta U^{v}+\Delta C_{r s d}
\end{aligned}
$$

Among them, $i$ is the period based on. Here, the choice of the weight period is arbitrary, and the bipolar decomposition algorithm solves the above-mentioned problem of the arbitrary choice of the weight period. The decomposition result is:

$$
\begin{gathered}
\Delta C_{T}=\frac{1}{2} F\left[\left(T_{t}-T_{0}\right) L_{t} U_{t}^{S} U_{t}^{v}+\left(T_{t}-T_{0}\right) L_{0} U_{0}^{S} U_{0}^{v}\right] \\
\Delta C_{L}=\frac{1}{2} F\left[T_{t}\left(L_{t}-L_{0}\right) U_{0}^{S} U_{0}^{v}+T_{0}\left(L_{t}-L_{0}\right) U_{t}^{S} U_{t}^{v}\right] \\
\Delta C_{U S}=\frac{1}{2} F\left[T_{t} L_{t}\left(U_{t}^{S}-U_{0}^{S}\right) U_{0}^{v}+T_{0} L_{0}\left(U_{t}^{S}-U_{0}^{S}\right) U_{t}^{v}\right] \\
\Delta C_{U^{v}}=\frac{1}{2} F\left[T_{t} L_{t} U_{t}^{S}\left(U_{t}^{v}-U_{0}^{v}\right)+T_{0} L_{0} U_{0}^{S}\left(U_{t}^{v}-U_{0}^{v}\right)\right]
\end{gathered}
$$

\subsection{Data preparation and processing}

The data in the input-output table in this article are for 2007, 2012 and 2017, because the data in the input-output table are all calculated at current prices. In order to ensure the comparability of prices, the data of 2012 and 2017 are converted into data with the constant price of 2007.In order to be consistent with the sectors in the final energy consumption by industry in the China Energy Statistical Yearbook, the input-output tables of 42 sectors in 2007 , 2012 and 149 sectors in 2017 were merged into the inputoutput tables of 26 sectors. The carbon emission factor is taken as 0.68 tons of carbon per ton of standard coal calculation.

\section{Analysis of decomposition results}

In terms of contribution rate, energy intensity effect shows significant negative effect, Leontief technology effect and total final demand effect are the main factors of carbon emission increase, and the structural effect of final demand is relatively small. From 2007 to 2012, energy intensity is the only factor to reduce carbon dioxide emissions. From 2012 to 2017 , the contribution rate of the final demand structure effect has also become negative, becoming another factor restraining the growth of carbon emissions. Although the proportion is relatively low, it is of great significance. It means that the final demand structure is changing in the direction of green and lowcarbon development. The decrease of the proportion of energy intensity effect shows that the decrease proportion of energy intensity from 2017 to 2012 is less than that from 2012 to 2007 . In the future, the further reduction of energy intensity can not only rely on the adjustment of factor structure, but also be realized by the progress of industry technology.

The energy intensity effect has the main inhibitory effect on the change of carbon emissions. This reflects that China has changed from the simple and extensive economic growth mode which relied on a large amount of resources to obtain economic benefits in the past to a highquality economic development mode. In this process, the above-mentioned industries have changed more obviously, with significant negative effects.

From the perspective of Leontief technology effect, this effect plays a role in promoting the change of carbon emissions during this period. The production technology of food processing and tobacco processing industry, electronic equipment manufacturing industry and service industry has been adjusted rapidly, and the energy consumption has been greatly changed. In general, changes in the input-output structure have continued to increase carbon emissions for a period of time, and China's production structure adjustment still has a long way to go. The change of demand structure has a pull-up effect on carbon emissions in this period, and the overall impact is relatively small. Consumption expenditure is the main factor affecting carbon emissions in the total final demand change, followed by total capital formation and exports. The relative changes of consumption 
Table 1 Decomposition results of China's carbon emission structure from 2007 to 2017 (10,000 tons of carbon)

\begin{tabular}{|c|c|c|c|c|c|c|c|}
\hline industry & $\begin{array}{l}\text { Energy intens } \\
\text { effect }\end{array}$ & & $\begin{array}{l}\text { Leontief technology } \\
\text { effect }\end{array}$ & & $\begin{array}{c}\text { demand structure } \\
\text { effect }\end{array}$ & total demand effe & \\
\hline $\begin{array}{l}\text { Agriculture, forestry, } \\
\text { animal husbandry and } \\
\text { fishery }\end{array}$ & -9851. & 68 & 3077. & 32 & 109.78 & 870. & 30 \\
\hline $\begin{array}{l}\text { Coal mining and dressing } \\
\text { industry }\end{array}$ & -113 & 39 & 59. & 07 & 3. 28 & -839 & 51 \\
\hline $\begin{array}{l}\text { Oil and gas production } \\
\text { and processing industry }\end{array}$ & -102 & 22 & 41. & 96 & 1. 99 & -351 & 29 \\
\hline $\begin{array}{l}\text { Metal mining and } \\
\text { beneficiation }\end{array}$ & -37 & 08 & 26. & 84 & 1. 71 & -545 & 07 \\
\hline $\begin{array}{l}\text { Non-metallic minerals and } \\
\text { other mining and dressing } \\
\text { industries }\end{array}$ & -44 & 75 & 22. & 57 & 1. 23 & -304 & 55 \\
\hline $\begin{array}{l}\text { Food manufacturing and } \\
\text { tobacco processing }\end{array}$ & -21401 & 93 & 5702. & 01 & 154. 79 & 37213. & 60 \\
\hline $\begin{array}{l}\text { Textile industry and other } \\
\text { fiber products industry }\end{array}$ & -10336 & 01 & 3759. & 74 & 160. 39 & -18168 & 24 \\
\hline $\begin{array}{l}\text { Wood and processing } \\
\text { industry }\end{array}$ & -2982. & 02 & 930. & 02 & 33. 11 & 315. & 80 \\
\hline $\begin{array}{l}\text { Paper printing and } \\
\text { stationery manufacturing } \\
\text { industry }\end{array}$ & -3176 & 95 & 834. & 42 & 21. 96 & 5955. & 29 \\
\hline $\begin{array}{l}\text { Petroleum processing, } \\
\text { coking and nuclear fuel } \\
\text { processing industries }\end{array}$ & -1343. & 06 & 379. & 10 & 11. 52 & 1571. & 10 \\
\hline $\begin{array}{l}\text { Chemical raw materials } \\
\text { and chemical products } \\
\text { manufacturing industry }\end{array}$ & -6805 & 49 & 2172 & 71 & 79. 83 & -1084 & 10 \\
\hline $\begin{array}{l}\text { Non-metallic mineral } \\
\text { manufacturing industry }\end{array}$ & -1098 & 33 & 368. & 37 & 14. 39 & -811 & 62 \\
\hline $\begin{array}{l}\text { Metal smelting and rolling } \\
\text { manufacturing }\end{array}$ & -1668. & 28 & 841. & 97 & 45. 90 & -11379 & 84 \\
\hline Metal products industry & -2623 & 00 & 946. & 83 & 40. 08 & -4348 & 55 \\
\hline $\begin{array}{l}\text { General and special } \\
\text { equipment manufacturing } \\
\text { industry }\end{array}$ & -13727 . & 57 & 4536. & 83 & 174. 15 & -7726 & 00 \\
\hline $\begin{array}{l}\text { Transportation equipment } \\
\text { manufacturing industry }\end{array}$ & - 15971 & 18 & 4385 . & 62 & 126. 62 & 23082 . & 47 \\
\hline $\begin{array}{l}\text { Electrical, mechanical and } \\
\text { equipment manufacturing }\end{array}$ & -7752 & 82 & 2674 & 46 & 107. 91 & -8395 & 41 \\
\hline $\begin{array}{l}\text { Communication } \\
\text { equipment, computer and } \\
\text { other electronic equipment } \\
\text { manufacturing industry }\end{array}$ & -16222 . & 58 & 5526. & 82 & 219. 88 & -15073 & 19 \\
\hline $\begin{array}{l}\text { Instrumentation and other } \\
\text { manufacturing industries }\end{array}$ & -1700 & 45 & 1067. & 88 & 64. 64 & - 19131 & 82 \\
\hline $\begin{array}{l}\text { Power and heat production } \\
\text { and supply industry }\end{array}$ & -1097. & 99 & 424. & 18 & 19. 15 & -2820 & 33 \\
\hline Gas production and supply & -598 & 56 & 289. & 89 & 15. 43 & -3644 & 76 \\
\hline $\begin{array}{l}\text { Water production and } \\
\text { supply }\end{array}$ & -322 & 36 & 88. & 46 & 2. 55 & 468. & 06 \\
\hline construction & -69392. & 09 & 18190. & 68 & 476. 60 & 131333 & 26 \\
\hline $\begin{array}{l}\text { Transportation, } \\
\text { warehousing and postal } \\
\text { industry }\end{array}$ & -9465 & 85 & 2343. & 83 & 53. 30 & 22858. & 10 \\
\hline $\begin{array}{l}\text { Wholesale and retail trade } \\
\text { catering industry }\end{array}$ & -18123 & 72 & 5223 & 02 & 164. 66 & 17344. & 19 \\
\hline Other services & -92365 & 55 & 23462 . & 96 & $570 . \quad 53$ & 201760 & 23 \\
\hline
\end{tabular}

expenditure and export show that China is gradually reducing its economic dependence on foreign countries and relying more on domestic consumption and investment.

The change of total demand effect has the largest contribution rate to carbon emissions. Transportation 
equipment manufacturing industry, food manufacturing industry, tobacco processing industry, construction industry and service industry showed obvious positive effects. The growth effect of total amount promoted the growth of carbon emissions. In this period, the total demand effect of most industrial sectors is negative, but the overall positive effect shows that the growth rate of most industrial sectors is still slower than that of the above sectors.

\section{Carbon emission influence coefficient and sensitivity coefficient}

Refer to $\mathrm{Gu}$ Alun's introduction of the influence coefficient and inductance coefficient on carbon emissions.

$$
\begin{gathered}
C F_{j}=\frac{c \sum_{i=1}^{n} e_{t} \overline{b_{i j}}}{c \frac{1}{n} \sum_{j=1}^{n} \sum_{i=1}^{n} e_{t} \overline{b_{i j}}}(j=1,2, \cdots, n) \\
C E_{i}=\frac{c \sum_{j=1}^{n} \overline{b_{i j}} e_{t}^{\prime}}{c \frac{1}{n} \sum_{i=1}^{n} \sum_{j=1}^{n} \overline{b_{i j}} e_{t}^{\prime}}(i=1,2, \cdots, n)
\end{gathered}
$$

In the left formula, $c$ is the carbon emission coefficient per unit of terminal energy consumption; ${ }^{e_{t}}$ is the row vector representing the energy intensity of sector $t ; e_{t}$ is its transposition; the upper half represents the full demand for carbon emissions of the national economy when the final use of sector $j$ is increased by one unit; the lower half represents the mean value of the complete demand for carbon emissions of the national economy when the final use of sector $j$ changes by one unit. The upper part of the right formula represents the complete demand for the carbon emissions of sector $i$ when the final use of each sector of the national economy is increased by one unit of change; the lower part represents the total economic the full demand average of sectoral carbon emissions.

The calculated results show: the impact of petroleum processing and coking and nuclear fuel processing industries, chemical raw materials and chemical products manufacturing, non-metallic mineral manufacturing, metal smelting and rolling manufacturing, power and heating production and supply industry, transportation, storage and postal industry The power coefficient and the inductance coefficient are relatively significant; the coal mining and dressing industry, the oil and gas mining and dressing industry, the metal mining and dressing industry, the non-metallic mining and other mining and dressing industries, and the water production and supply industry have significant influence coefficients. The coefficient is relatively insignificant; the inductance coefficients of the construction industry and other service industries are more significant, while the influence coefficients are relatively small; while the influence coefficients and inductance coefficients of the remaining other industries are relatively small.

\section{Conclusion}

From the beginning of 2007 to 2017 , the carbon emissions generated by various industries in China increased from $167,787,700$ tons of carbon to $297,589.22$ tons of carbon. Among the four factors that led to the changes in China's carbon emissions growth from 2007 to 2017.The energy intensity effect is the main restraining factor. During this period, the energy intensity effect caused a decrease in the proportion of carbon emissions, indicating that the energy intensity of various industries is declining and is gradually shifting to high-quality economic growth. The Leontief inverse matrix effect and the total final demand effect are factors that pull up the growth of carbon dioxide emissions The effect of the final demand structure is not significant during this period.

The influence coefficients of most industrial sectors are relatively high, so many industrial sectors need to be paid attention to in future energy conservation and emission reduction policies. However, it is also necessary to consider that many basic industrial sectors are the lifeblood of the national economy, such as energy industries such as coal mining and processing, chemical raw materials and chemical product manufacturing, metal smelting and rolling manufacturing, transportation, storage, and postal industries. Adjustments need to be coordinated with changes in the country's overall economic structure, and more emphasis should be placed on the technological progress of the industry to achieve the goal of carbon emission reduction. Non-metallic mining and other mining and dressing industries, instrumentation manufacturing and other manufacturing industries, water production and supply industries and other sectors with high influence coefficients but low inductance coefficients, because the increase in final demand in other sectors will lead to less the increase in carbon emissions and the increase in its own final demand will lead to a large increase in carbon emissions in other sectors, so the proportion of these industries can be appropriately reduced under the premise of ensuring demand. Service industries with relatively low influence and inductance, such as wholesale and retail, catering, and high-end manufacturing, such as electrical equipment manufacturing, communication equipment, computer and other electronic equipment manufacturing, should become key development sectors in the future.

\section{Reference}

1. Yang Wu, Wang Ben, Xiang Dingxian, et al. Decomposition of carbon emission factors of energy consumption and low carbon development in Wuhan City[J].Population, resources and environment in China, 2018,28(S1):13-16.

2. Xu Guoquan, Liu Zeyuan, Jiang Zhaohua. Factor Decomposition Model and Empirical Analysis of China's Carbon Emissions: 1995-2004 [J]. Population, resources and environment in China, 2006(6) :158161.

3. Zhu Qin, Peng Xizhe, Lu Zhiming, et al. Decomposition and Empirical Analysis of Factors 
Decomposing China's Energy Consumption Carbon Emission Changes [J].Resource science, 2009, 31(12):2072-2079.

4. LEONTIEF W W D. Ford. Air pollution and economic structure[J].Contributions to Input- Output Analysis, 1972.

5. Zha Jianping, Tan Ting, Qian Xingbao, et al. China's tourism carbon emission and its driving factors decomposition [J]. Systems engineering, 2018, 36(05):23-36 